\title{
Situational characteristics of young adults' eating occasions: a real-time data collection using Personal Digital Assistants
}

\author{
Melissa Nelson Laska ${ }^{1, *}$, Dan Graham ${ }^{1}$, Stacey G Moe ${ }^{1}$, Leslie Lytle ${ }^{1}$ and \\ Jayne Fulkerson ${ }^{2}$ \\ 'School of Public Health, Division of Epidemiology and Public Health, University of Minnesota, \\ 1300 S. 2nd Street - Suite 300, Minneapolis, MN 55454, USA: ${ }^{2}$ School of Nursing, \\ University of Minnesota, Minneapolis, MN, USA
}

Submitted 26 August 2010: Accepted 5 October 2010: First published online 8 December 2010

\begin{abstract}
Objective: To examine (i) situational characteristics of young adults' eating occasions, including away-from-home eating, social influences and multi-tasking, and (ii) how these characteristics are associated with specific foods/beverages consumed.

Design: Participants logged numerous characteristics of eating occasions ( $n$ 1237) in real time over $7 \mathrm{~d}$.

Setting: Minneapolis/St. Paul metropolitan area (Minnesota, USA).

Subjects: Forty-eight participants, aged 18-23 years.

Results: Half of all eating occasions (46\%) occurred alone, 26\% occurred while watching television and $36 \%$ involved other multi-tasking. Most participants $(63 \%)$ did not think about their food choices in advance of eating occasions. Eating that occurred in the absence of television viewing and/or other multitasking was less likely to include sweetened beverages and more likely to include items like water, fruit, vegetables, cereal, grains and entrées. Eating occasions occurring alone, and/or those occurring at home, were more likely to include snack foods that required little preparation (e.g. cookies, baked goods) and less likely to include more traditional meal items (e.g. fruits, vegetables, entrée items). Conclusions: Overall, a large proportion of young adults' eating occasions occurred alone, while engaging in other activities and with little advanced planning. Although many young adults' eating occasions consist of a wide range of highly processed, energy-dense, convenience products, more traditional meal settings (i.e. eating at home with others in the absence of multi-tasking) may result in more structured mealtimes and better food choices, such as more fruits and vegetables. Effective behavioural strategies promoting positive eating patterns, including home meal preparation, are urgently needed among young adults.
\end{abstract}

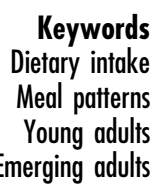

Obesity is a major public health concern ${ }^{(1,2)}$. The transition from adolescence to adulthood is recognized as an influential age for excess weight gain, marked by poor dietary patterns and physical inactivity ${ }^{(3)}$. This age also represents an important time when many individuals move out of their family home, relocate to new environments and establish independent lifestyles. However, little scholarly work to date has examined the determinants of dietary behaviours and weight gain during this age ${ }^{(3)}$. In particular, we know little about the contextual factors influencing eating and food choices among young adults. Given the unique attributes of the young adult years ${ }^{(3)}$, exploratory research is needed to better characterize meal patterns and the contextual factors associated with food choices that are most relevant to young adults' lives.
Previous research suggests that the frequency of family meals is positively associated with dietary quality and other favourable outcomes among both children and adolescents $^{(4-9)}$. However, once adolescents graduate from high school and begin to establish lifestyles independent from their families, their mealtime patterns may decline substantially in quality and structure and may shift to irregular times. Young adults are among the most frequent consumers of fast food, convenience products and nutrient-poor dietary choices compared with other age groups (see Nelson $e t$ al. $^{(3)}$ for a recent review of this literature). A significant proportion of young adults report eating 'on the run' and recent research suggests that such a style of eating is consistently associated with less favourable nutritional factors ${ }^{(10)}$. Furthermore, few young 
adults engage in some of the key practices known to contribute to healthy dietary intake, like home food preparation and meal planning ${ }^{(11)}$.

Overall, scant research to date has examined issues around young adults' meal patterning in detail, and nutrition promotion interventions in young adults are urgently needed. However, in order to develop these types of behavioural intervention strategies and appropriate nutrition education messages for young adults, we first need a better understanding of young adults' meal patterns, including the characteristics of and factors surrounding their meals and eating occasions. To address these gaps in the literature, the purposes of the present study were to examine: (i) the situational characteristics of young adults' eating occasions including away-from-home eating, social influences, multi-tasking during meals and timing of eating occasions; and (ii) how these situational characteristics were associated with specific types of foods/beverages consumed at meals and snacks.

\section{Methods}

\section{Participants}

Young adulthood represents a diverse set of lifestyle characteristics; thus, we recruited forty-eight participants (18-23 years, twenty-seven females) during 2008-2009 from four lifestyle groups: (i) attending college/university and living on campus ( $n$ 12); (ii) attending college/ university and living independently from parents/family (off campus) ( $n 12$ ); (iii) attending college/university and living with parents ( $n 12$ ); and (iv) not attending college/ university and living independently from parents/family ( $n$ 12). Participants were recruited by posting flyers throughout 2- and 4-year colleges/universities, in coffee houses and shops and on local websites (e.g. Craig's List) frequented by young adults in the Minneapolis/St. Paul area. Participants were instructed to call or email study staff, who then assessed their eligibility for participation in the study. Study procedures were approved by the University of Minnesota Institutional Review Board.

\section{Procedure}

In study visits at the University of Minnesota, participants completed a thirty-eight-item survey assessing food purchasing habits and relevant behaviours, and were given a Palm ${ }^{\circledR}$ Z22 handheld Personal Digital Assistant (PDA) device (http://www.palm.com/) to record their consumption of foods and beverages for the $7 \mathrm{~d}$ period between the two study visits. PDA devices were pre-programmed for food log entry using Pendragon Forms software (http:// www.pendragonsoftware.com/). Participants were instructed to log every eating (and/or drinking) occasion during a $7 \mathrm{~d}$ period, as soon after the eating occasion concluded as possible. A pre-programmed script led participants through a series of fourteen items used to characterize eating occasions, including the following.

1. Start and end time of the eating occasion.

2. Location type: e.g. home, workplace or school/ university.

3. Social context ('Who was/is with you?'): e.g. by myself, one or more friends, or one or more family members.

4. Food/beverages consumed.

5. Other activities while eating: e.g. watching television or using a computer; hereafter referred to as 'multitasking'.

6. Pre-planning of food choices. Participants were asked: 'Did you specifically think about what you would eat before you started eating? When did you start thinking about which foods or beverages you would select?' Response options included: 'No, just beforehand', 'Yes, about 30 minutes', 'Yes, a few hours before' and 'Yes, more than a few hours before'.

Drop-down menus, including pre-set, categorical response options with an 'other' category (which allowed for open-text entry), were available for nearly all questions. However, food and beverage entries were recorded entirely in free-text form, allowing participants to include appropriate descriptors of the food/beverages that they consumed. To minimize participant burden, beverages were recorded only if participants drank more than 1 cup $(8 \mathrm{oz})$ at one sitting. Participants were given detailed written instructions and in-person tutorials on how to use the PDA. Qualitative exit interviews with participants indicated that they were able to easily navigate the PDA program and felt comfortable doing so.

Other relevant data were self-reported by participants in the survey form; these data included sociodemographic characteristics and current living situations.

\footnotetext{
Analysis

Analyses consisted of descriptive sample characteristics of young adults' eating occasions (away-from-home eating, social context, multi-tasking during meals, timing of eating occasions), as well as how these situational characteristics were associated with specific types of foods/ beverages consumed at meals and snacks. In all analyses, the unit of analysis was eating occasion; there were 1237 eating occasions among the forty-eight participants, with each participant reporting multiple eating occasions over the measurement week. The food data were coded using pre-existing categories adapted from existing protocols for another study which used PDA to collect food-related data (Away from home and out of school: adolescent physical activity and BMI changes occurring with driving and eating out, Principal Investigator: DA Cohen). Each food item recorded by a participant was placed in one category (e.g. 'muffin' was categorized as 'Cookies and sweetened baked goods'). Categories were available for food items that were missing detail; for example, 'milk'
} 
was coded as 'Milk', while if a participant indicated that they drank 'skimmed milk' the category for 'Skimmed milk' was used. We did not attempt to document portion size of foods consumed.

All analyses controlled for the nested nature of the data (i.e. the multiple observations per participant). Logistic regression analyses were utilized to calculate all $P$ values (e.g. to determine whether the percentages of participants eating and drinking specific foods and beverages at home were significantly different from the percentages of participants eating and drinking these foods and beverages away from home). In analyses comparing eating occasions that occurred at home $v$. away from home, participants living on college campuses ( $n$ 12) were considered to be eating 'at home' when eating on campus and 'away from home' when off campus. Preliminary analyses stratified by living situation indicated that in-home $v$. away-from-home comparisons were similar among participants not living on campus ( $n 36$ ) and those living in dormitories ( $n$ 12); thus, for the ease of interpretation, these groups were combined and results were presented for the sample as a whole.

Analyses were conducted using SPSS version $17 \cdot 0$ (SPSS Inc., Chicago, IL, USA) and STATA version $8 \cdot 0$ (Stata Corporation, College Station, TX, USA) statistical software packages.

\section{Results}

Nearly half of the study participants were male (44\%; Table 1). Mean age was approximately 21 years and $83 \%$ of the sample was white, reflecting the overall geographic region. By design, participants represented a range of lifestyle characteristics, including college enrolment status (not attending college, attending part-time, attending fulltime), employment status and living situation.

Table 2 describes the situational and contextual differences in eating occasions that occurred at home $v$. away from home. Overall, approximately half of the eating occasions (46\%) occurred alone, 26\% involved watching television and $36 \%$ involved activities other than television. Nearly $40 \%$ of eating occasions lasted less than $15 \mathrm{~min}$ and another $41 \%$ lasted $15-30 \mathrm{~min}$. For a majority of eating occasions (63\%), participants did not think about what they would eat or drink until immediately prior to the eating occasion. More than half (51\%) of all eating events occurred between 11 am and $7 \mathrm{pm}$, another quarter (24\%) occurred between $7 \mathrm{pm}$ and midnight, $21 \%$ occurred between $5 \mathrm{am}$ and $11 \mathrm{am}$, and the remaining $4 \%$ of eating occasions were recorded between midnight and $5 \mathrm{am}$.

Compared with eating occasions that occurred away from home, at-home eating events were more likely to occur alone and to be accompanied by television viewing $(P \leq 0 \cdot 001$; Table 2). At-home eating occasions were also
Table 1 Descriptive characteristics of the study sample: young adults aged $18-23$ years $(n 48)$, Minneapolis/St. Paul metropolitan area (Minnesota, USA)

\begin{tabular}{lrr}
\hline & $\%$ & $n$ \\
\hline Gender & & \\
Male & 44 & 21 \\
Female & 56 & 27 \\
Age (years) & & \\
18 & 15 & 7 \\
19 & 25 & 12 \\
20 & 19 & 9 \\
21 & 29 & 14 \\
22 & 10 & 5 \\
23 & 2 & 1 \\
Racet & & \\
White & 83 & 40 \\
Black or African American & 8 & 4 \\
Asian, Native Hawaiian or other Pacific & 8 & 4 \\
$\quad$ Islander & & \\
American Indian or Alaska Native & 2 & 1 \\
Hispanic/Latino & 2 & 1 \\
College status & & \\
Not attending college & 25 & 12 \\
Attending college/university part-time & 13 & 6 \\
Attending college/university full-time & 62 & 30 \\
Employment status & \\
Not employed & 29 & 14 \\
Employed, <20 h/week & 40 & 19 \\
Employed, $\geq 20$ h/week & 31 & 15 \\
Living situation & \\
Living with parents & 25 & 12 \\
Living on a college or university campus & 25 & 12 \\
Living on own (in rented apartment/house & 50 & 24 \\
$\quad$ or own home) & & \\
\hline
\end{tabular}

†Not mutually exclusive; participants were instructed to select all that apply.

less likely to last at least $30 \mathrm{~min}(P \leq 0 \cdot 001)$, and participants eating at home were less likely to have thought about what they would eat a few hours or more in advance of at-home eating $(P \leq 0 \cdot 05)$. In addition, a significantly larger proportion of away-from-home eating occasions occurred in the very early morning (between midnight and $5 \mathrm{am}$ ), whereas a significantly larger proportion of at-home eating occasions occurred during typical breakfast hours ( 5 am to 11 am; $P \leq 0 \cdot 05$ ).

Table 3 details the types of foods and beverages consumed at home $v$. away from home. Eating occasions at home were more likely to include cookies and baked goods, milk, cereals and grains, but were less likely to include calorically sweetened beverages, entrée items and fried side dishes $(P \leq 0 \cdot 05)$. Among participants living in dormitories, on-campus (compared with off-campus) eating occasions were more likely to include fruits and vegetables ( $44 \% v .28 \%$, respectively) and milk (28\%v $11 \%)$, but less likely to include calorically sweetened beverages ( $11 \%$ v. $25 \%)$ and salty snacks (13\% v. $25 \%$; all $P \leq 0 \cdot 05$, data not shown).

Table 4 displays the extent to which the types of foods consumed at each eating occasion varied by situational characteristics, including social context and multi-tasking. Overall, eating occasions that occurred alone ( $v$. with others) were more likely to include snack 
Table 2 Descriptive characteristics of eating occasions among the study sample: young adults aged 18-23 years ( $n$ 48), Minneapolis/ St. Paul metropolitan area (Minnesota, USA)

\begin{tabular}{|c|c|c|c|}
\hline & \multirow[b]{2}{*}{$\begin{array}{l}\text { Total }(\%) \\
(n 1237)\end{array}$} & \multicolumn{2}{|c|}{ Location of eating occasion (\%) } \\
\hline & & $\begin{array}{l}\text { Home } \\
(n \text { 892) }\end{array}$ & $\begin{array}{l}\text { Away from home } \\
\qquad(n 345)\end{array}$ \\
\hline Eating occasions logged on PDA & 100 & 100 & 100 \\
\hline \multicolumn{4}{|l|}{ Social context } \\
\hline By myself & 46 & 51 & $35^{\star \star}$ \\
\hline With friends or family & 54 & 49 & $65^{\star \star}$ \\
\hline \multicolumn{4}{|l|}{ Other activities while eating } \\
\hline Not doing anything else (or talking in person with others) & 57 & 54 & $65^{*}$ \\
\hline Watching televisiont & 26 & 30 & $15^{\star \star \star}$ \\
\hline Activities other than watching televisiont & 36 & 36 & 38 \\
\hline \multicolumn{4}{|l|}{ Duration of eating occasion } \\
\hline Less than $15 \mathrm{~min}$ & 37 & 39 & 32 \\
\hline $15-30 \mathrm{~min}$ & 41 & 44 & $34^{\star \star \star}$ \\
\hline More than $30 \mathrm{~min}$ & 17 & 13 & $27^{\star \star \star}$ \\
\hline \multicolumn{4}{|l|}{$\begin{array}{l}\text { When did you starting thinking about what foods you would select } \\
\text { for this meal/snack? }\end{array}$} \\
\hline Just before starting to eat & 63 & 65 & 58 \\
\hline About $30 \mathrm{~min}$ before & 23 & 23 & 24 \\
\hline A few hours or more before & 12 & 10 & $16^{*}$ \\
\hline \multicolumn{4}{|l|}{ Timing of eating occasion (time of day) } \\
\hline $7 \mathrm{pm}$ to midnight & 24 & 24 & 25 \\
\hline Midnight to $5 \mathrm{am}$ & 4 & 3 & $5^{*}$ \\
\hline 5 am to $11 \mathrm{am}$ & 21 & 23 & $15^{*}$ \\
\hline $11 \mathrm{am}$ to $7 \mathrm{pm}$ & 51 & 50 & 55 \\
\hline
\end{tabular}

PDA, Personal Digital Assistant.

All values above are calculated based on the total eating occasions logged by forty-eight participants, except where otherwise noted.

Significant differences in eating characteristics within sub-categories of location (i.e. home $v$. away from home), controlling for multiple observations among individual participants: ${ }^{\star} P \leq 0.05,{ }^{\star \star} P<0.01,{ }^{\star \star \star} P<0.001$.

tCategories are not mutually exclusive (i.e. participants could report watching television as well as doing other activities, including using a computer, talking on the phone, text messaging, etc.).

foods such as cookies and sweetened baked goods, but were less likely to include calorically sweetened beverages, fruits and vegetables, entrée items and fried side dishes (all $P \leq 0 \cdot 05$ ). Eating occasions that occurred in a more 'traditional' meal setting (e.g. eating that occurred while not doing anything else, or while talking in person with others) were less likely to include calorically sweetened beverages and coffee/tea, and were more likely to include healthier meal items (such as water, fruit, vegetables, cereal and grains) as well as entrée items and fried side dishes, compared with eating events that occurred while watching television or multi-tasking $(P \leq 0 \cdot 05)$.

Table 5 details the differences in the types of foods consumed by time of day. Compared with eating occasions that occurred between $11 \mathrm{am}$ and $7 \mathrm{pm}$, those occurring late at night ( $7 \mathrm{pm}$ to midnight) and/or in the early morning (midnight to $5 \mathrm{am}$ ) were less likely to include milk, fruits and vegetables, and entrée items, and were more likely to include salty snacks $(P \leq 0 \cdot 05)$. Eating occasions occurring between 5 am and 11 am were less likely than those occurring between 11 am and 7 pm to include calorically sweetened beverages, salty snacks, fresh fruits and vegetables, entrée items and fried side dishes, and were more likely to include coffee or tea drinks, milk, cookies and sweetened baked goods, and cereals and grains $(P \leq 0 \cdot 05)$.

\section{Discussion}

The purpose of the current research was to examine situational characteristics of young adults' eating occasions including away-from-home eating, social influences, multi-tasking during meals and timing of eating occasions, as well as to examine how these situational characteristics were associated with specific types of foods and beverages consumed throughout the day. Participants in the study logged various characteristics of all eating occasions ( $n$ 1237) over a one-week period. The findings in our young adult sample indicate that a large proportion of eating occasions occurred alone, while watching television or engaging in other activities; were completed within a 15 min time frame; and occurred with virtually no pre-contemplation or planning of food choices or meal selections. Previous research indicates that factors such as planning one's meals ahead of time and eating in the absence of other activities (e.g. television viewing) may be key determinants of healthy dietary patterns ${ }^{(12,13)}$; as such, these may be important target areas for future nutrition promotion interventions among young adults.

In addition, these findings indicated that among young adults, at-home eating occasions were associated with higher intakes of certain snacks and convenience foods (such as cookies and sweetened baked goods) and fewer 
Table 3 Types of foods consumed by location of eating occasion among the study sample: young adults aged 18-23 years ( $n$ 48), Minneapolis/St. Paul metropolitan area (Minnesota, USA)

\begin{tabular}{|c|c|c|c|c|}
\hline & \multirow[b]{2}{*}{ Examples of foods/beverages included in sub-category } & \multirow[b]{2}{*}{$\begin{array}{l}\text { Total (\%) } \\
(n 1237)\end{array}$} & \multicolumn{2}{|c|}{ Location of eating occasion (\%) } \\
\hline & & & $\begin{array}{l}\text { Home } \\
(n \text { 892) }\end{array}$ & $\begin{array}{l}\text { Away from home } \\
\qquad(n 345)\end{array}$ \\
\hline Eating occasions logged on PDA & & 100 & 100 & 100 \\
\hline \multicolumn{5}{|l|}{ Beverages (non-alcoholic) } \\
\hline Calorically sweetened & $\begin{array}{l}\text { Regular soda (not diet), energy drinks, juice drinks } \\
\text { (not } 100 \% \text { juice), sports drinks, soda (no details } \\
\text { given), juice drinks (no details given) }\end{array}$ & 15 & 12 & $21^{\star *}$ \\
\hline Water & Water (no details given) & 17 & 16 & 17 \\
\hline Coffee or tea drinks & $\begin{array}{l}\text { Plain coffee, cappuccino, latte, specialty coffee } \\
\text { drinks, tea (flavoured or unflavoured, hot or iced) }\end{array}$ & 9 & 9 & 8 \\
\hline $\begin{array}{r}\text { Milk } \\
\text { Foods }\end{array}$ & Milk: skimmed, $1 \%, 2 \%$, whole; plain or flavoured & 20 & 24 & $8^{\star \star \star}$ \\
\hline $\begin{array}{l}\text { Cookies and sweetened } \\
\text { baked goods }\end{array}$ & $\begin{array}{l}\text { Animal crackers, graham crackers, cereal bars, } \\
\text { energy/protein bars, cookies, doughnuts, cinnamon } \\
\text { rolls, churro, granola bars, cakes, pies, brownies, } \\
\text { muffins, scones, biscuits, Rice Krispie treats }\end{array}$ & 32 & 36 & $23^{\star \star \star}$ \\
\hline $\begin{array}{l}\text { Candy and gummy fruit } \\
\text { snacks }\end{array}$ & $\begin{array}{l}\text { Candy bars, hard candies, jelly beans, taffy, caramel, } \\
\text { chewing gum }\end{array}$ & 5 & 4 & 6 \\
\hline Salty snacks & $\begin{array}{l}\text { Potato chips, crackers, beef jerky, popcorn, pretzels, } \\
\text { snack mixes, nuts, seeds, nachos }\end{array}$ & 13 & 12 & 16 \\
\hline Fruits and vegetables & $\begin{array}{l}\text { Fresh fruit, fresh vegetables or salad, } 100 \% \text { juice, } \\
\text { canned fruit, pickles, caramel apple, apple sauce, } \\
\text { dried fruit, baked/mashed potato, guacamole, salsa }\end{array}$ & 31 & 32 & 31 \\
\hline Frozen desserts & $\begin{array}{l}\text { Frozen yoghurt, popsicles, Italian ice, ice cream, } \\
\text { frozen fruit juice }\end{array}$ & 3 & 2 & 3 \\
\hline $\begin{array}{l}\text { Non-milk dairy products } \\
\text { (non-frozen) }\end{array}$ & $\begin{array}{l}\text { Cream cheese, pudding, cheese, yoghurt (not frozen), } \\
\text { smoothie, shakes }\end{array}$ & 11 & 12 & 10 \\
\hline Entrées & $\begin{array}{l}\text { Frozen dinners, tacos, quesadillas, pizza, pizza rolls, } \\
\text { sandwiches, wraps, hamburgers, cheeseburgers, } \\
\text { soup, chilli, sushi, chicken nuggets or wings, pasta, } \\
\text { hot dogs, Chinese food, pork, beef, fish/seafood, } \\
\text { poultry, tofu/tempeh, eggs, buffet, casserole }\end{array}$ & 43 & 41 & $49^{*}$ \\
\hline Cereals and grains & $\begin{array}{l}\text { Granola/oatmeal, breakfast cereals, bagels, bread, } \\
\text { breadsticks, rice, waffles, pancakes, French toast }\end{array}$ & 28 & 33 & $17^{\star \star \star}$ \\
\hline Fried side dishes & $\begin{array}{l}\text { French fries, tater tots, hash browns, potato skins, fried } \\
\text { mozzarella sticks, onion rings }\end{array}$ & 5 & 4 & $9^{\star \star \star}$ \\
\hline
\end{tabular}

PDA, Personal Digital Assistant.

Some categories (low-energy beverages, other beverages, alcohol) are not included in the table because of their small sample size (i.e. appearing on thirty PDA records or fewer for the full sample).

Significant differences in eating characteristics within sub-categories of location (i.e. home $v$. away from home), controlling for multiple observations among individual participants: ${ }^{\star} P \leq 0.05,{ }^{\star \star} P<0 \cdot 01,{ }^{\star \star \star} P<0.001$.

traditional meal items (such as entrées, fruits and vegetables) as compared with away-from-home eating occasions. These results may represent a phenomenon that is somewhat unique to this age group. Overall, nearly half of all adults in the USA report eating three or more meals each week that have been prepared commercially away from home ${ }^{(14)}$, including a large proportion from fastfood restaurants ${ }^{(15)}$. Compared with meals prepared at home, commercially prepared meals have been shown generally to contain more energy, fat, sodium and cholesterol, as well as lower levels of beneficial nutrients (e.g. fibre, calcium) ${ }^{(16)}$. Given that the young adult age group is among the most frequent consumer of fast food and convenience food products ${ }^{(3)}$, these issues present serious concerns that may, at least in part, account for the substantial excess weight gain and poor nutritional status observed at this age. Of even greater concern, however, is the fact that young adults may be becoming increasingly ill-equipped to prepare healthy meals at home, lacking the knowledge, skills, resources, time and/or motivation to prepare food on their own ${ }^{(11)}$. Our findings highlight the fact that many young adults are consuming foods at home that require little to no preparation, such as cookies, baked goods and cereal, and may be lacking the fundamental knowledge and skills equipping them to cook healthy meals at home. The significance of these issues is underscored by the fact that these are young adults of reproductive age who soon may be starting families of their own.

Findings from the present study also suggest that more traditional meal settings (i.e. eating with others in the absence of multi-tasking) may be associated with several healthier dietary characteristics, including the consumption of more fruits and vegetables and/or fewer cookies and sweetened baked goods. Previous research has shown that although a majority of young adults enjoy and 
Table 4 Types of foods consumed by contextual characteristics of eating occasions among young adults aged 18-23 years ( $n$ 48), Minneapolis/St. Paul metropolitan area (Minnesota, USA)

\begin{tabular}{|c|c|c|c|c|c|}
\hline & \multicolumn{2}{|c|}{ Social context† (\%) } & \multicolumn{3}{|c|}{ Other activities while eating $\neq(\%)$} \\
\hline & $\begin{array}{l}\text { By myself } \\
\text { ( } n \text { 572) }\end{array}$ & $\begin{array}{l}\text { With others } \\
\quad(n \text { 665) }\end{array}$ & $\begin{array}{l}\text { Not doing anything } \\
\text { else (or talking in } \\
\text { person with others) } \\
\text { ( } n \text { 707) }\end{array}$ & $\begin{array}{c}\text { Watching } \\
\text { television } \\
(n \text { 322) }\end{array}$ & $\begin{array}{l}\text { Other } \\
\text { activities } \\
(n 447)\end{array}$ \\
\hline Eating occasions logged on PDA & 100 & 100 & 100 & 100 & 100 \\
\hline \multicolumn{6}{|l|}{ Beverages (non-alcoholic) } \\
\hline Calorically sweetened & 10 & $18^{*}$ & 15 & $24^{\star *}$ & 13 \\
\hline Water & 19 & 15 & 17 & $12^{*}$ & 17 \\
\hline Coffee or tea drinks & 10 & 8 & 6 & 5 & $13^{\star \star}$ \\
\hline Milk & 19 & 20 & 23 & 23 & 11 \\
\hline \multicolumn{6}{|l|}{ Foods } \\
\hline Cookies and sweetened baked goods & 37 & $28^{\star \star}$ & 33 & 29 & 31 \\
\hline Candy and gummy fruit snacks & 4 & 5 & 5 & 5 & 7 \\
\hline Salty snacks & 12 & 14 & 14 & 15 & 17 \\
\hline Fruits and vegetables & 27 & $35^{\star}$ & 36 & $26^{\star \star}$ & $27^{\star \star}$ \\
\hline Fresh fruits/vegetables & 19 & $26^{*}$ & 27 & $16^{\star \star}$ & $18^{\star \star}$ \\
\hline Other & 12 & $16^{\star}$ & 16 & 12 & 13 \\
\hline Frozen desserts & 2 & 3 & 3 & 3 & 3 \\
\hline Non-milk dairy products (non-frozen) & 11 & 11 & 11 & 10 & $11^{\star *}$ \\
\hline Entrées & 33 & $52^{\star \star}$ & 49 & 46 & $32^{* *}$ \\
\hline Cereals and grains & 30 & 27 & 31 & $25^{\star}$ & $22^{*}$ \\
\hline Fried side dishes & 3 & $7^{*}$ & 7 & 4 & $2^{* *}$ \\
\hline
\end{tabular}

PDA, Personal Digital Assistant.

Significant differences in food types within sub-categories of social context and activities while eating, controlling for multiple observations among individual participants: ${ }^{\star} P \leq 0.05,{ }^{\star \star} P<0 \cdot 01$

tFor social context, statistically significant differences are compared with 'by myself' as the reference group in analyses.

fFor activities while eating, statistically significant differences are compared with 'not doing anything else (or talking in person with others)' as the reference group in analyses. 'Other activities' designation comprised the following self-reported responses: using a computer, driving/riding in vehicle, reading, talking on phone/text message, and other. Categories are not mutually exclusive (i.e. participants could report watching television as well as doing other activities, including using a computer, talking on the phone, text messaging, etc.).

Table 5 Types of foods consumed by across various times of day among young adults aged $18-23$ years $(n$ 48), Minneapolis/St. Paul metropolitan area (Minnesota, USA)

\begin{tabular}{|c|c|c|c|c|}
\hline & \multicolumn{4}{|c|}{ Time of eating occasion (\%) } \\
\hline & $\begin{array}{c}7 \mathrm{pm} \text { to midnight } \\
(\text { ( } 297)\end{array}$ & $\begin{array}{l}\text { Midnight to } 5 \text { am } \\
\qquad(n 47)\end{array}$ & $\begin{array}{l}5 \text { am to } 11 \text { am } \\
(n 250)\end{array}$ & $\begin{array}{l}11 \text { am to } 7 \mathrm{pm} t \\
(n \text { 623) }\end{array}$ \\
\hline Eating occasions logged on PDA & 100 & 100 & 100 & 100 \\
\hline \multicolumn{5}{|l|}{ Beverages (non-alcoholic) } \\
\hline Calorically sweetened & 17 & 21 & $6^{\star *}$ & 17 \\
\hline Water & 16 & 32 & 14 & 18 \\
\hline Coffee or tea drinks & 8 & 13 & $16^{\star *}$ & 6 \\
\hline Milk & $8^{*}$ & $6^{*}$ & $34^{\star \star}$ & 20 \\
\hline \multicolumn{5}{|l|}{ Foods } \\
\hline Cookies and sweetened baked goods & 26 & 19 & $52^{\star \star}$ & 28 \\
\hline Candy and gummy fruit snacks & 7 & 6 & 1 & 4 \\
\hline Salty snacks & $20^{*}$ & 13 & $2^{\star \star}$ & 14 \\
\hline Fruits and vegetables & $23^{\star \star}$ & $11^{\star \star}$ & 30 & 36 \\
\hline Fresh fruits/vegetables & $15^{\star \star}$ & $6^{\star *}$ & $17^{\star \star}$ & 29 \\
\hline Other & 10 & 4 & 17 & 15 \\
\hline Frozen desserts & 3 & 4 & $<1^{\star}$ & 3 \\
\hline Non-milk dairy products (non-frozen) & 10 & 4 & 10 & 12 \\
\hline Entrées & $39^{* *}$ & $30^{* *}$ & $18^{\star *}$ & 57 \\
\hline Cereals and grains & 18 & 19 & $52^{\star \star}$ & 24 \\
\hline Fried side dishes & 6 & 4 & $2^{*}$ & 6 \\
\hline
\end{tabular}

PDA, Personal Digital Assistant.

Significant differences in food types within sub-categories of time of eating occasion, controlling for multiple observations among individual participants: ${ }^{\star} P \leq 0.05,{ }^{* \star} P<0.01$.

tFor time of eating occasion, statistically significant differences are compared with ' 11 am to 7 pm' as the reference group in analyses.

fFor a limited number of eating occasions ( $n 20,1 \cdot 6 \%)$, time was not recorded.

value eating with others, many report a lack of time to sit down and eat structured meals with others ${ }^{(10)}$. Research by Larson et al. from Project EAT (Eating Among Teens), a large population-based cohort study of adolescents transitioning into young adulthood, has shown that eating meals with others is associated with better overall dietary 
quality, including higher intakes of fruits, vegetables, calcium and fibre, as well as lower intakes of fat and saturated fat ${ }^{(10)}$. These findings are also supported by a growing body of research suggesting that children and adolescents who report more frequent family meals have more favourable intakes of fruits, vegetables and several key nutrients ${ }^{(5)}$. Overall, more effort is needed to support young adults in engaging in thoughtful and healthful food choices. Encouraging structured meal settings that are socially engaging may be an important mechanism through which these behaviours could be supported.

Although we found that most young adults' eating occasions occurred during the day (11 am to $7 \mathrm{pm}$ ), a notable proportion occurred later at night. Approximately one-quarter of eating events occurred between $7 \mathrm{pm}$ and midnight, and a relatively small proportion (4\%) occurred between midnight and $5 \mathrm{am}$. Late-night eating events were less likely to include healthier items such as fruits, vegetables and milk, and more likely to consist of salty snacks eaten away from home. Limiting the excess energy consumed during late-night eating events may be an important issue to be addressed among young adults in order to prevent weight gain over time. In general, promoting healthy choices during typical breakfast hours may also be needed among young adults; our findings indicate that young adults who ate breakfast during these hours were more likely to make some healthier choices (e.g. more cereals, grains, milk) and were less likely to make others (e.g. more sweetened baked goods, less fresh fruit).

Recently, there has been a widespread call to 'Bring back home economics education', as described in the recent editorial in the Journal of the American Medical Association with this title by Lichtenstein and Ludwig ${ }^{(17)}$. Frequent home food preparation has been associated with better dietary outcomes among both adolescents and young adults ${ }^{(11,18)}$ and is often cited as a critical skill that is lacking among these age groups. Interestingly, however, recently national survey data indicate that the proportion of students enrolled in Family and Consumer Science (i.e. 'home economics') programmes in US secondary schools has not changed since the $1950 \mathrm{~s}^{(19)}$. It is unlikely that these courses alone are sufficient in equipping adolescents to begin a life-long habit of healthy home food preparation. More intensive effort needs to be invested in helping adolescents and emerging adults develop the skills by which to prepare healthy meals at home on most nights of the week, to sustain such long-term healthful lifestyle habits and to cope with the obesogenic environments in which we live. Comprehensive efforts will need to be targeted not only within schools, but also within family, home and community settings.

Nutrition promotion efforts that are specifically targeted towards young adults are urgently needed. The findings from the present research provide a better understanding of the contexts in which young adults eat, which is important in developing more relevant nutrition promotion interventions and nutrition education messaging for this age group. Although we are lacking data on specific nutrient intake within our study, many of the food and beverage items recorded by participants on the PDA food logs were generally energy-dense and not of high nutritional quality. For example, many of the entrées reported here could be described as 'convenience foods' and/or 'fast foods', including frozen dinners, tacos, pizza, hamburgers, chicken fingers and wings. Different dietary assessment methods (e.g. $24 \mathrm{~h}$ recalls) are needed in future studies to explore the nutrient composition of participants' dietary intakes in a more precise way. Although our data collection methodology was limited in this respect, it allowed us to capture a wide range of contextual characteristics that occur around mealtimes, which are not typically available from $24 \mathrm{~h}$ dietary recalls. In addition, qualitative exit interviews conducted in our study suggested that participants may have been able to more readily log this wide array of mealtime factors due to the real-time nature of the data collection.

An additional important limitation of the present study is the small sample size. Despite the fact that data were collected on over 1200 eating events, these data were collected from forty-eight young adult participants, which limits our ability to examine differences within specific subgroups of participants (e.g. by gender, age group or lifestyle characteristics). Although future research is needed among larger samples to explore these issues in greater depth, such data collection among large samples may be logistically challenging, particularly given that the scoring of these data (e.g. categorizing food types) can be a very time-intensive and laborious process for research staff. Therefore, these time- and labour-intensive methods may be best utilized for small-scale, exploratory and hypothesis-generating research studies, which may then inform more targeted data collection in larger samples. For example, it would be possible to add data collection on a limited number of specific contextual features of interest to $24 \mathrm{~h}$ dietary recall data collection within larger study samples, in order to obtain meal-specific data on contextual factors. In addition, carefully obtained $24 \mathrm{~h}$ recall data may also be used to better understand the association between the timing of eating occasions throughout the day and overall dietary quality.

In summary, additional work is needed to promote healthy, at-home food preparation and eating among young adults and in the population as a whole. In a recently released report, the 2010 US Dietary Guidelines Advisory Committee identified nine key changes that are needed in the overall food environment in order to support Americans in meeting the recommendations of the Dietary Guidelines. The first change identified in their report is to 'improve nutrition literacy and cooking skills, including safe food handling skills, and empower and motivate the population ... to prepare and consume healthy foods at home ${ }^{,(20)}$. The transition from adolescence 
to young adulthood may be an important age for acquiring and reinforcing these skills ${ }^{(11,18)}$. Overall, this is a particularly influential developmental age for excess weight gain and poor dietary habits ${ }^{(3)}$ and most young adults fail to meet national recommendations for health. Establishing more structured and routine meal patterns and preparing healthy foods at home are major challenges for many young adults today. Effective strategies to promote healthy eating patterns, including home meal preparation, are urgently needed among young adults.

\section{Acknowledgements}

Additional supplementary study materials are publicly available online (http://www.sph.umn.edu/facstaff/ourfaculty/ f_res.asp?PID=493\&fn= Melissa $\% 20$ Nelson $\% 20$ Laska $)$, including PDF documents that contain all of the content contained in the PDA screens viewed by study participants, as well as written instructions given to participants for use with the PDA protocol.

Funding for the study was provided by the National Cancer Institute (NCI), Transdisciplinary Research in Energetics \& Cancer Initiative (NCI Grant 1 U54 CA116849-01, Examining the Obesity Epidemic Through Youth, Family and Young Adults, Principal Investigator: Robert Jeffery). Additional support was provided by Award Number K07CA126837 from NCI (Principal Investigator: Melissa Nelson Laska). The content of the present manuscript is solely the responsibility of the authors and does not necessarily represent the official views of NCI. NCI did not play a role in designing the study, collecting the data or analysing/interpreting the results.

The authors have no conflicts of interest to declare. M. N. L. conceived the idea, designed and directed the study, and led the writing of the manuscript. D. G. conducted the statistical analyses. S. G. M. led data collection, study administration and food data coding. L. L. helped develop the food coding system. M. N. L., D. G., S. G. M., L. L. and J. F. all contributed to the interpretation of findings and critical revision of the manuscript. The authors would like to thank Anne Samuelson, Pamela Carr and Dawn Ann Nelson for their assistance with data collection and coding, as well as Andrew Odegaard for his assistance with PDA data programming and processing.

\section{References}

1. Flegal KM, Carroll MD, Ogden CL et al. (2010) Prevalence and trends in obesity among US adults, 1999-2008. JAMA 303, 235-241.

2. Ogden CL, Carroll MD, Curtin LR et al. (2010) Prevalence of high body mass index in US children and adolescents, 2007-2008. JAMA 303, 242-249.
3. Nelson M, Story M, Larson N et al. (2008) Emerging adulthood and college-aged youth: an overlooked age for weight-related behavior change. Obesity (Silver Spring) 16, 2205-2211.

4. Larson NI, Neumark-Sztainer D, Hannan PJ et al. (2007) Family meals during adolescence are associated with higher diet quality and healthful meal patterns during young adulthood. J Am Diet Assoc 107, 1502-1510.

5. Neumark-Sztainer D, Larson NI, Fulkerson JA et al. (2010) Family meals and adolescents: what have we learned from Project EAT (Eating Among Teens)? Public Health Nutr 13, 1113-1121.

6. Fulkerson JA, Kubik MY, Story M et al. (2009) Are there nutritional and other benefits associated with family meals among at-risk youth? J Adolesc Health 45, 389-395.

7. Fulkerson JA, Neumark-Sztainer D, Hannan PJ et al. (2008) Family meal frequency and weight status among adolescents: cross-sectional and 5-year longitudinal associations. Obesity (Silver Spring) 16, 2529-2534.

8. Fulkerson JA, Story M, Neumark-Sztainer D et al. (2008) Family meals: perceptions of benefits and challenges among parents of 8- to 10-year-old children. J Am Diet Assoc 108, 706-709.

9. Boutelle KN, Fulkerson JA, Neumark-Sztainer D et al. (2007) Fast food for family meals: relationships with parent and adolescent food intake, home food availability and weight status. Public Health Nutr 10, 16-23.

10. Larson NI, Nelson MC, Neumark-Sztainer D et al. (2009) Making time for meals: meal structure and associations with dietary intake in young adults. J Am Diet Assoc 109, $72-79$.

11. Larson NI, Perry CL, Story M et al. (2006) Food preparation by young adults is associated with better diet quality. $J \mathrm{Am}$ Diet Assoc 106, 2001-2007.

12. Crawford D, Ball K, Mishra G et al. (2007) Which foodrelated behaviours are associated with healthier intakes of fruits and vegetables among women? Public Health Nutr 10, 256-265.

13. Barr-Anderson DJ, Larson NI, Nelson MC et al. (2009) Does television viewing predict dietary intake five years later in high school students and young adults? Int J Behav Nutr Phys Act 6, 7.

14. Kant AK \& Graubard BI (2004) Eating out in America, 1987-2000: trends and nutritional correlates. Prev Med 38, 243-249.

15. Larson NI, Neumark-Sztainer DR, Story MT et al. (2008) Fast food intake: longitudinal trends during the transition to young adulthood and correlates of intake. $J$ Adolesc Health 43, 79-86.

16. Guthrie JF, Lin BH \& Frazao E (2002) Role of food prepared away from home in the American diet, 1977-78 versus 1994-96: changes and consequences. J Nutr Educ Behav 34, 140-150.

17. Lichtenstein AH \& Ludwig DS (2010) Bring back home economics education. JAMA 303, 1857-1858.

18. Larson NI, Story M, Eisenberg ME et al. (2006) Food preparation and purchasing roles among adolescents: associations with sociodemographic characteristics and diet quality. J Am Diet Assoc 106, 211-218.

19. Werhan C \& Way W (2006) Family and consumer sciences programs in secondary schools: results of a national survey. J Fam Consum Sci 98, 19-25.

20. US Department of Agriculture, Center for Nutrition Policy and Promotion (2010) Report of the Dietary Guidelines Advisory Committee on the Dietary Guidelines for Americans, 2010. http://www.cnpp.usda.gov/DGAs2010-DGACReport.htm (accessed July 2010). 